\title{
Poor accuracy of freehand cup positioning during total hip arthroplasty
}

\author{
B. H. Bosker - C. C. P. M. Verheyen • \\ W. G. Horstmann • N. J. A. Tulp
}

Received: 12 February 2006 / Published online: 13 February 2007

(C) Springer-Verlag 2007

\begin{abstract}
Several studies have demonstrated a correlation between the acetabular cup position and the risk of dislocation, wear and range of motion after total hip arthroplasty. The present study was designed to evaluate the accuracy of the surgeon's estimated position of the cup after freehand placement in total hip replacement. Peroperative estimated abduction and anteversion of 200 acetabular components (placed by three orthopaedic surgeons and nine residents) were compared with measured outcomes (according to Pradhan) on postoperative radiographs. Cups were placed in $49.7^{\circ}$ (SD 6.7) of abduction and $16.0^{\circ}$ (SD 8.1) of anteversion. Estimation of placement was $46.3^{\circ}$ (SD 4.3) of abduction and $14.6^{\circ}$ (SD 5.9) of anteversion. Of more interest is the fact that for the orthopaedic surgeons the mean inaccuracy of estimation was $4.1^{\circ}$ (SD 3.9) for abduction and $5.2^{\circ}$ (SD 4.5) for anteversion and for their residents this was respectively, 6.3 ${ }^{\circ}$ (SD 4.6) and $5.7^{\circ}$ (SD 5.0). Significant differences were found between orthopaedic surgeons and residents for inaccuracy of estimation for abduction, not for anteversion. Body mass index, sex, (un)cemented fixation and surgical approach (anterolateral or posterolateral) were not significant factors. Based upon the inaccuracy of estimation, the group's chance on future cup placement
\end{abstract}

No benefits or funds were received in support of this study.

B. H. Bosker · C. C. P. M. Verheyen ( () .

W. G. Horstmann · N. J. A. Tulp

Department of Orthopaedic Surgery and Traumatology,

Isala Clinics, Weezenlanden Hospital, P.O. Box 10500,

8000 GM Zwolle, The Netherlands

e-mail: c.c.p.m.verheyen@isala.nl within Lewinnek's safe zone $\left(5-25^{\circ}\right.$ anteversion and $30-50^{\circ}$ abduction) is 82.7 and $85.2 \%$ for anteversion and abduction separately. When both parameters are combined, the chance of accurate placement is only $70.5 \%$. The chance of placement of the acetabular component within $5^{\circ}$ of an intended position, for both abduction and anteversion is $21.5 \%$ this percentage decreases to just $2.9 \%$ when the tolerated error is $1^{\circ}$. There is a tendency to underestimate both abduction and anteversion. Orthopaedic surgeons are superior to their residents in estimating abduction of the acetabular component. The results of this study indicate that freehand placement of the acetabular component is not a reliable method.

Keywords Freehand cup positioning - Accuracy · Total hip arthroplasty

\section{Introduction}

Acetabular cup position after total hip arthroplasty is correlated with the risk of dislocation, wear and range of motion [1-6]. Lewinnek et al. [7] described a safe range (5-25 anteversion and $30-50^{\circ}$ abduction) to position the cup. Within this range the dislocation rate was $1.5 \%$ and outside this range $6.1 \%$. Although the position of the cup is important for the prognosis and function of the hip, most surgeons place the cup without any specific guidance devices. During surgery the surgeon estimates the position of the acetabular component and decides if it meets the desired orientation before securing it.

In this study the accuracy of the surgeons peroperative estimation of the position of the cup is evaluated. 


\section{Materials and methods}

All patients undergoing primary total hip arthroplasty were enrolled in the study. Patient characteristics as name, sex, age, operated side and the body mass index were recorded. All cooperating surgeons (three orthopaedic surgeons and nine residents) received a list on which the following data concerning the operation were recorded: fixation (cemented or uncemented), cup model, surgical approach, complications and the peroperative estimated anteversion and abduction of the acetabular component.

Two days after the operation two standardised Xrays were made. One anteroposterior X-ray was taken with the beam centered over the hip, the second was a plain AP radiograph centred on the symphisis, showing both hips. Radiographic cup anteversion was measured on the first radiograph, according to Pradhan [8], and cup abduction was assessed on the second by measuring the angle between the teardrop line and the line bisecting the opening of the acetabular cup. The combination of both radiographs was used to determine if a cup was in the ante- or retroverted position, as described by Flabeck et al. [9].

For both anteversion and abduction, the inaccuracy of estimation was determined by calculating the difference between peroperative estimation and postoperative X-ray measurements. Mean values and standard deviations were calculated for measured cup position, estimated cup position and inaccuracy of estimation. A comparison of these values was assessed between orthopaedic surgeons and residents, using student's $t$ test $(P<0.05$ assumed as significant $)$ and a multivariate linear regression analysis was applied on the data in order to investigate which factors influenced the inaccuracy of estimation.

\section{Results}

Two hundred cups in 194 patients, placed between June 2003 and May 2005, were included in the study. There were 55 males and 139 females. At time of operation the mean age of the patients was 72.4 years (3492) with a mean body mass index of 27.5 (16.6-38.1). The cups were placed by 12 different surgeons. Eightyfive cups $(42.5 \%)$ were placed by three orthopaedic surgeons and $115(57.5 \%)$ by 9 of their residents, always under supervision of one of the surgeons.

One hundred and fifty-seven $(78.5 \%)$ cups had a cemented and $43(21.5 \%)$ an uncemented fixation; 89 $(44.5 \%)$ cups were placed in the patients' right hip and $111(55.5 \%)$ in the left. Two surgical approaches were used. The anterolateral approach according to Mallory was used in 57 cups $(28.5 \%)$, supervised by one orthopaedic surgeon and the postero-lateral approach by the other two surgeons in 143 cups $(71.5 \%)$. The residents used the approach of their supervising surgeon. For the anterolateral approach according to Mallory, mean placement of the cup was in $11.8^{\circ}$ anteversion and $47.1^{\circ}$ abduction. Positioning of the cup differed significantly when a posterolateral approach was applied: $17.7^{\circ}$ anteversion and $50.7^{\circ}$ abduction (both $P<0.001$ ). Comparing both anterolateral and posterolateral approaches, no significant differences were found for inaccuracy of estimation for either anteversion $\left(4.9^{\circ} \mathrm{vs}\right.$. $5.5^{\circ}$, respectively) or abduction $\left(5.3^{\circ}\right.$ vs. $\left.6.1^{\circ}\right)$.

Table 1 shows relevant data of estimations and the measurements of the acetabular component by both orthopaedic surgeons and residents. None of the cups was placed in retroversion.

From the data from which Fig. 1 was constructed, it was derived that 129 cups $(64.5 \%)$ were placed within $5^{\circ}$ of the estimated abduction, for anteversion this was the case in 122 cups (61\%). There is a tendency to underestimate both abduction and anteversion.

Table 2 demonstrates the results of the chance for cup placement according to Lewinnek $\left(5-25^{\circ}\right.$ anteversion and $30-50^{\circ}$ abduction), based upon inaccuracy of estimation for the orthopaedic surgeons, their residents and the group in total. Virtual intended cup placement was set at $15^{\circ}$ anteversion and $40^{\circ}$ abduction. Only $56.5 \%$ of the cups were placed in this safe zone according to their measured abduction and anteversion. Table 3 shows the percentage for the group and orthopaedic surgeons and residents separately, for cup placement within different ranges $(20,10,5,2.5$ and $1^{\circ}$ ) of an intended cup position $X$.

A multivariate regression analysis was applied in order to identify any factors that might be responsible for the inaccuracy of the estimation. A significant result was found for abduction and anteversion, concerning age of the patient and if the patient was operated by an orthopaedic surgeon or resident. Other factors like body mass index, sex, operated side, (un)cemented fixation of the acetabular component, model of the cup and the surgical approach did not reveal any significant differences.

\section{Discussion}

Malposition of the acetabular cup is probably the most important factor for dislocation of a total hip prosthesis. Therefore it is essential that the surgeon has maximum control over the position of the socket during the 
Table 1 Mean estimated and measured anteversion and abduction

\begin{tabular}{|c|c|c|c|c|c|}
\hline & \multirow[t]{2}{*}{ Cups $N$} & \multicolumn{2}{|c|}{ Anteversion (degrees) } & \multirow[t]{2}{*}{ Difference } & \multirow[t]{2}{*}{ Mean inaccuracy of estimation } \\
\hline & & Estimated & Measured & & \\
\hline \multicolumn{6}{|l|}{ Ia } \\
\hline Orthopedic surgeon & 85 & 14.5 & 14.7 & -0.2 & $5.2(\mathrm{SD} 4.5)$ \\
\hline Residents & 115 & 14.7 & 16.9 & -2.2 & $5.7(\mathrm{SD} 5.0)$ \\
\hline Total & 200 & $14.6(\mathrm{SD} 5.9)$ & $16.0(\mathrm{SD} 8.1)$ & -1.4 & 5.5 \\
\hline \multirow[t]{3}{*}{ Significance } & & - & - & - & - \\
\hline & Cups $N$ & \multicolumn{2}{|l|}{ Abduction } & \multirow[t]{2}{*}{ Difference } & \multirow[t]{2}{*}{ Mean inaccuracy of estimation } \\
\hline & & Estimated & Measured & & \\
\hline \multicolumn{6}{|l|}{$\mathrm{Ib}$} \\
\hline Orthopedic surgeon & 85 & 47.2 & 48.6 & -1.4 & $4.09(\mathrm{SD} 3.9)$ \\
\hline Residents & 115 & 45.6 & 50.5 & -4.9 & $6.28(\mathrm{SD} 4.6)$ \\
\hline Total & 200 & $46.3(\mathrm{SD} 4.3)$ & $49.7(\mathrm{SD} 6.7)$ & -3.4 & 5.4 \\
\hline Significance & & 0.001 & 0.043 & 0.000 & 0.001 \\
\hline
\end{tabular}

Fig. 1 Results of the distribution of the difference between the estimated and measured values (degrees) for abduction (a) and anteversion (b) of the acetabular components $(N)$
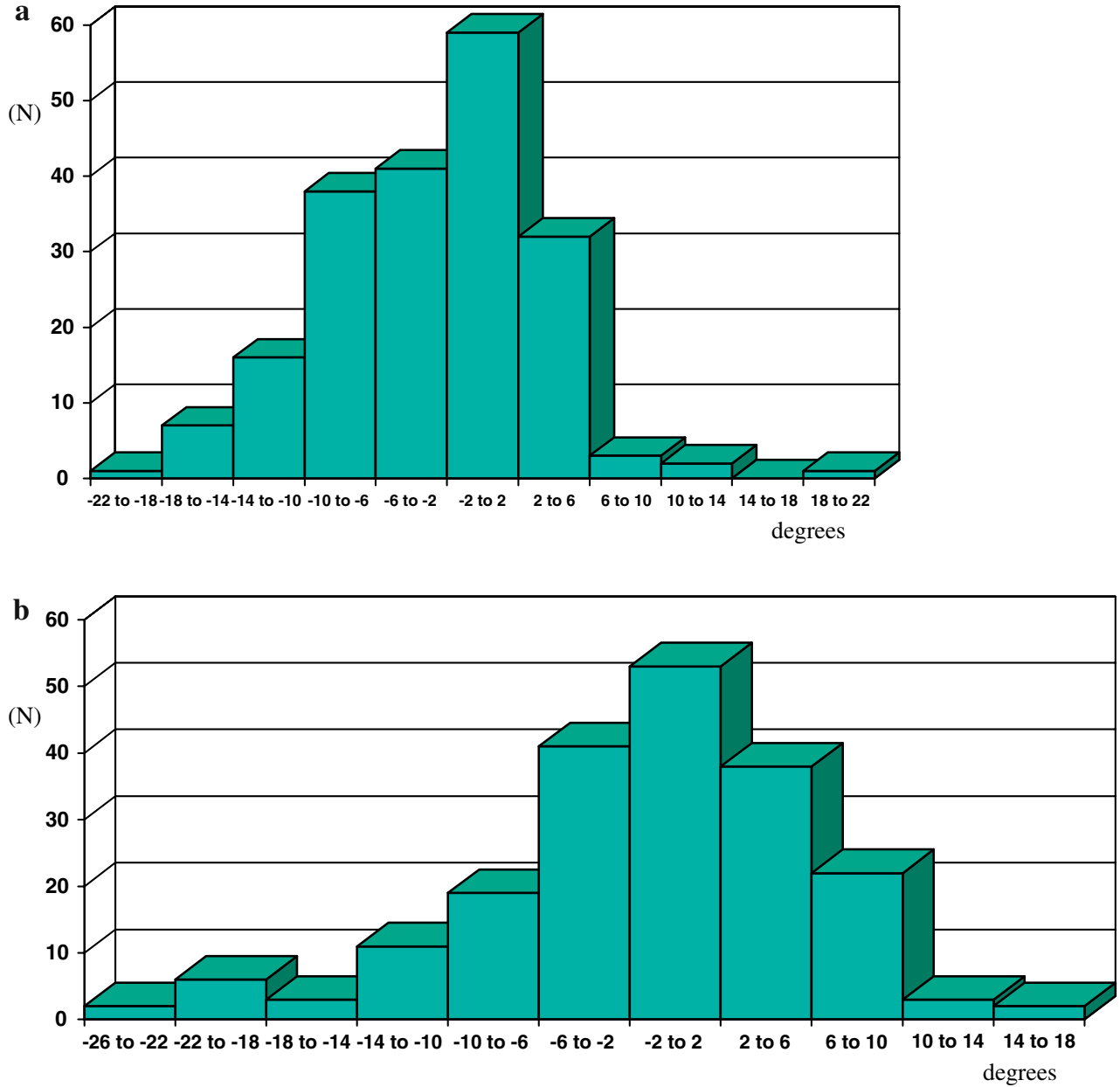

operation. Free hand positioning with the patient in a standardized position and a cup positioner with the patient and floor as reference is the routine method. Specific mechanical alignment guides were designed to add precision, as do navigation systems in the concept of CT-guided computer-assisted surgery. Surprisingly, there are very limited data on the precision rate of free hand positioning of the acetabular shell. The aim of our prospective study was to determine the accuracy of the free hand technique. Only then the presently 
Table 2 Results of the chance for cup placement within the limits according to Lewinnek (5-25 anteversion and $30-50^{\circ}$ abduction) for the orthopedic surgeons, their residents and the entire group. Intended cup placement was virtually set on $15^{\circ}$ anteversion and $40^{\circ}$ abduction

\begin{tabular}{llll}
\hline & $\begin{array}{l}\text { Anteversion } \\
(\%)\end{array}$ & $\begin{array}{l}\text { Abduction } \\
(\%)\end{array}$ & $\begin{array}{l}\text { Placement } \\
\text { according to } \\
\text { Lewinnek }(\%)\end{array}$ \\
\hline $\begin{array}{l}\text { Orthopedic } \\
\text { surgeons }\end{array}$ & 85.7 & 93.7 & 80.3 \\
$\begin{array}{l}\text { Residents } \\
\text { Group }\end{array}$ & 80.5 & 78.9 & 63.5 \\
\hline
\end{tabular}

introduced systems can be tested against this standard. The term "free hand" is not used uniformly in the literature. Either it is referred to pure manual positioning or with the aid of the acetabular cup impactor-positioner provided with the implant. In the present study, the latter definition was applied.

One comparable study is that of Saxler et al. [10] who showed, in a retrospective CT-controlled design, that 27 out of their 105 cups $(25.7 \%)$ were placed within the safe zone of Lewinnek. A second study by DiGioa et al. [11] with a specific mechanical acetabular alignment guide (with A-frame) where the results were controlled peroperatively with a hip navigation system in 74 hips aimed at $45^{\circ}$ of abduction and $20^{\circ}$ of flexion. With their specific guide only $22 \%$ of the cups were placed within Lewinneks safe zone. Compared with these two studies our prospective data demonstrate an accuracy within the safe zone of $70.5 \%$.

There is an elegant in vitro study by Jolles et al. [12] comparing free hand (without the help of any guide), mechanical alignment guide and computer-assisted cup placement. Onehunderd and fifty acetabular implants were placed in ten identical models of the pelvis (covered with artificial soft tissue of soft cast and foam) by ten surgeons. The mean accuracy for anteversion was $8^{\circ}(5.0-10.5)$ for free hand with cup positioner and $4^{\circ}$
(3.0-5.5) for abduction; with computer navigation this was $1.5^{\circ}(1.0-2.0)$ and $2.5^{\circ}(2.0-3.5)$, respectively. In the present in vivo study the data were $5.5^{\circ}$ for anteversion and $5.4^{\circ}$ for abduction with 200 acetabular shells. Jolles et al. state that their in vitro conditions of ideal approach and anatomic relations and perfect placement of the patient would favour the free hand positioning as computer-assisted surgery devices are only slightly sensitive to modifications of these parameters and inaccuracy of the freehand will be enhanced greatly in vivo. Our study proves this statement not to be the case as results are quite comparable.

Without doubt it is essential to actually place what is aimed for. Our present study shows that the $70.5 \%$ positioned within the safe zone is remarkably good for free hand placement compared with literature. But when the target is reset from the wide safe zone of Lewinnek to for instance within $5^{\circ}$ or even $1^{\circ}$ of error from the judged position for both abduction and anteversion, only 21.5 and $2.9 \%$ of our sockets are placed within this narrow definition of safe zone. We believe that the power of our study comes from the distinctive set up where the recorded data are a reflection of the surgeon's perception of cup placement. To our opinion this is superior then to allow for a wide range or set a predefined target. At the actual point of cup placement a surgeon is also committed to or governed by the patient's anatomy, which will influence the actual position. For instance when less anteversion is accepted in the socket; the stem will be given some additional anteversion.

Another important item as stipulated by DiGioia et al. [11] is the actual position of the patient in the lateral decubitus position. They demonstrated that the mean difference of pelvic orientation on the operating table with the desired position during acetabular alignment was $18^{\circ}$ in version and $3^{\circ}$ in abduction. This effect is not completely eliminated with the use of computer navigation as these systems are influenced by pelvic tilt [13].
Table 3 Deviation in \% of cup placement in between $20^{\circ}$, $10^{\circ}, 5^{\circ}, 2.5^{\circ}$ and $1^{\circ}$ of position $X$ for the entire group (orthopaedic surgeons and residents): (a), the orthopaedic surgeons: (b) and the residents: (c)

\begin{tabular}{llllll}
\hline & $X \pm 20(\%)$ & $X \pm 10(\%)$ & $X \pm 5(\%)$ & $X \pm 2.5(\%)$ & $X \pm 1(\%)$ \\
\hline $\begin{array}{llll}\text { (a) Group } \\
\text { Abduction }\end{array}$ & 100 & & & & \\
Anteversion & 99.9 & 85.2 & 46.8 & 26 & 16.4 \\
Combined & 99.9 & 70.5 & 46 & 26.7 & 17.5 \\
(b) Surgeon & & & 21.5 & 6.9 & 2.9 \\
Abduction & 100 & 93.7 & 59.3 & 34 & 21.2 \\
Anteversion & 99.9 & 85.7 & 48.3 & 27.5 & 17.6 \\
Combined & 99.9 & 80.3 & 28.6 & 9.4 & 3.7 \\
(c) Residents & & & & & \\
Abduction & 99.8 & 78.9 & 39 & 20.7 & 12.7 \\
Anteversion & 99.8 & 80.5 & 44.5 & 26.2 & 17.4 \\
Combined & 99.6 & 63.5 & 17.4 & 5.4 & 2.2 \\
\hline
\end{tabular}


Considering the estimation of abduction, significant results were found in favour of the orthopaedic surgeons compared to their residents. A learning curve as a result of experience is probably responsible for this difference. As to surgical approach, acetabular components placed posterolaterally were measured to have a significantly higher-degree of anteversion and abduction. This is obviously related with the intention to minimize the change of a dislocation for both approaches. Although both approaches take a different anatomical route to the acetabulum, visualization and presentation of the acetabulum do not seem to be important factors. The conclusion is that an anterolateral or posterolateral approach is not a distinguishing factor in the accuracy of cup placement in our series.

An important potential flaw in this investigation is the use of planar radiographs for the evaluation of true abduction and especially anteversion. Variations in pelvic flexion-extension during imaging are responsible of variations in flexion up to $-26^{\circ}$ to $+10^{\circ}$ [14]. This study concludes that radiographic measurements are not a reliable method to evaluate cup orientation, especially flexion or anteversion alignment [14]. Pradhan, however, stated that his method, as used in our study, proved to be reliable in an in vitro model in which the calculated anteversion on the X-ray was compared with the true (known) cup anteversion. In our study special attention was given for optimal positioning of the patients pelvis to minimize rotation and tilt before the X-ray was taken. From a practical point of view it is preferable to determine the actual cup position with planar radiographs rather then with CT as in most clinics the availability and the costs of a CT scan combined with the high radiation dose for the patient are reasons for not using this instrument as a routine practice.

From this prospective study it is concluded that an accuracy of $70.5 \%$ for placement of the socket with an acetabular shell imactor-positioner within Lewinnek's safe zone and of only $21.5 \%$ within an error of $5^{\circ}$ for both abduction and anteversion is unacceptable.

The strength of our research is that literature is extremely scarce on studies as our prospective study on free hand positioning without special aiming devices. The results of the present study appear convincing but limitations are the high-number of participating surgeons, different surgical approaches (anterolateral and posterolateral) and two methods of cup fixation (uncemented and cemented). Multivariate analysis on these factors revealed only differences between the achievements of surgeons and residents.
The consequence of our conclusion that free hand cup positioning is an unreliable method is that attention now should be focussed on the results of a randomized trial comparing the different techniques of cup positioning.

\section{References}

1. McCollum DE, Gray WJ (1990) Dislocation after total hip arthroplasty. Causes and prevention. Clin Orthop Relat Res (261):159-170

2. Jolles BM, Zangger P, Leyvraz PF (2002) Factors predisposing to dislocation after primary total hip arthroplasty: a multivariate analysis. J Arthroplasty 17(3):282-288

3. Del Schutte H Jr, Lipman AJ, Bannar SM, Livermore JT, Ilstrup D, Morrey BF (1998) Effects of acetabular abduction on cup wear rates in total hip arthroplasty. J Arthroplasty 13(6):621-626

4. D'Lima DD, Urquhart AG, Buehler KO, Walker RH, Colwell CW Jr (2000) The effect of the orientation of the acetabular and femoral components on the range of motion of the hip at different head-neck ratios. J Bone Joint Surg Am 82(3):315-321

5. Widmer KH (2004) A simplified method to determine acetabular cup anteversion from plain radiographs. J Arthroplasty 19(3):387-390

6. Widmer KH, Zurfluh B (2004) Compliant positioning of total hip components for optimal range of motion. J Orthop Res 22(4):815-821

7. Lewinnek GE, Lewis JL, Tarr R, Compere CL, Zimmerman JR (1978) Dislocations after total hip-replacement arthroplasties. J Bone Joint Surg Am 60(2):217-220

8. Pradhan R (1999) Planar anteversion of the acetabular cup as determined from plain anteroposterior radiographs. J Bone Joint Surg Br 81(3):431-435

9. Fabeck L, Farrokh D, Tolley M, Descamps PY, Gebhart M, Delince P (1999) A method to measure acetabular cup anteversion after total hip replacement. Acta Orthop Belg 65(4):485-491

10. Saxler G, Marx A, Vandevelde D, Langlotz U, Tannast M, Wiese M, Michaelis U, Kemper G, Grutzner PA, Steffen R, von Knoch M, Holland-Letz T, Bernsmann K (2004) The accuracy of free-hand cup positioning-a CT based measurement of cup placement in 105 total hip arthroplasties. Int Orthop 28(4):198-201

11. Digioia AM III, Jaramaz B, Plakseychuk AY, Moody JE Jr, Nikou C, Labarca RS, Levison TJ, Picard F (2002) Comparison of a mechanical acetabular alignment guide with computer placement of the socket. J Arthroplasty 17(3):359-364

12. Jolles BM, Genoud P, Hoffmeyer P (2004) Computer-assisted cup placement techniques in total hip arthroplasty improve accuracy of placement. Clin Orthop Relat Res (426):174-179

13. Lembeck B, Mueller O, Reize P, Wuelker N (2005) Pelvic tilt makes acetabular cup navigation inaccurate. Acta Orthop 76(4):517-523

14. Jaramaz B, DiGioia AM 3rd, Blackwell M, Nikou C (1998) Computer assisted measurement of cup placement in total hip replacement. Clin Orthop Relat Res (354):70-81 